\title{
Detecção da frente de um Microburst com expoentes de Lyapunov em tempos finitos
}

\author{
Microburst front detection with finite time Lyapunov exponents
}

\author{
Nicasio Barrere, Cecilia Cabeza, Giuliano Demarco, Umberto Rizza, Vagner Anabor, Franciano \\ Scremin Puhales, Otávio Costa Acevedo
}

\begin{abstract}
Resumo
Microburst é um fenômeno que ocorre na atmosfera e consiste de uma coluna descendente intensa de ar que, depois de colidir com a superfície do solo, leva a ventos divergentes intensos. Esses ventos podem chegar a mais de $30 \mathrm{~ms}^{-1}$ e estão associados a forças de cisalhamento elevadas, o que representa uma séria ameaça para aeronaves e edifícios. A detecção e acompanhamento da parte frontal de um microburst ao nível do solo torna-se um interessante e importante campo para os pesquisadores. Trabalhos anteriores mostram a detecção do núcleo do vórtice de forma precisa porém, não para a frente do vórtice. A partir dos campos de velocidade obtidos a partir de uma simulação de LES, utilizou-se Expoentes Lyapunov em tempo finito (do inglês, FTLE), em que se mede a divergência exponencial entre trajetórias de partículas. Em seguida, identificou-se variedades que atuam como separadores do escoamento e representam o núcleo ou frente do vórtice. Ademais, ao rastrear a frente do vórtice, mediu-se o deslocamento desses vórtices ao longo do tempo. Encontrar a frente do vórtice utilizando-se apenas campos de velocidade e vórticidade é uma tarefa complicada e pouco precisa portanto, a combinação desses dois métodos representa representa uma nova aproximação nesse problema em particular.
\end{abstract}

Palavras-chave: Microburst, Vórtice, Expoentes de Lyapunov para tempos finitos, Estruturas lagrangeanas coerentes.

\begin{abstract}
A microburst is a phenomena that occurs in the atmosphere which consist on a very intense downdraft that, after impinging on the ground surface, leads to strongly divergent winds at and just above the ground level. Such winds can reach more than $30 \mathrm{~ms}^{-1}$ and are associated with high shear forces, representing a serious threat to aircrafts and buildings. The detection and tracking of the front of the microburst expansion at the ground level becomes an important and interesting field for researchers. Previous works show the detection of the vortex core but not for the vortex front. From velocity fields obtained from a LES simulation, we utilize Finite Time Lyapunov Exponents (FTLE) which measures the exponential divergence between particle trajectories. Then we identify manifolds which acts as separatrices of the flow and represent the edge or front of the vortex. By tracking the vortex front we also measure its displacement through time. Find the front of the vortex using only vorticity and velocity fields is complicated and imprecise. Therefore, the combination of these two methods represents a new approach in this particular problem.
\end{abstract}

Keywords: Microburst, Vortex, Finite Time Lyapunov Exponents, Lagrangian Coherent Structures. 


\section{Introduction}

A microburst is generated from a perturbation which cools the air in a very localized region of the atmosphere. The air becomes heavier than the surroundings and get a negative buoyancy which cause the localized downdraft. After it hits the ground, it generates divergent winds that expand radially over the ground and the propagation of vortex rings can be observed. Fujita was the first who suggest the idea of a descending downdraft. Fujita (1985) observed that the patterns on the ground did not match to the patterns of tornadoes as it was suspected. Since then, the microburst become an interesting area of research, specially for atmosphere researchers as well as engineers or even aircraft companies due to the threat that the microburst horizontal winds may represent. This winds can reach more than $30 \mathrm{~ms}^{-1}$ and several damage to civil structures and aircraft have been reported (Fujita, 1985, 1990; Holmes e Oliver, 2000; Lundgren et al., 2007). The study of microbursts have been in situ (Fujita, 1985, 1990), experimental (Proctor, 1988, 1989; Demarco et al., 2013; Holmes e Oliver, 2000; Lundgren et al., 2007) and numerical (Proctor, 1988, 1989; Lundgren et al., 2007). Those mentioned works have focused on the description of the microburst evolution and when studying the development and propagation of vortex ring a natural problem arises: how to detect the front of the vortex ring i.e. the front of the microburst. The natural approach from an eulerian perspective is to study velocity and vorticty fields (Demarco et al., 2013). The maximum of vorticity relates to the vortex core while the front of the vortex is at a distance unknown from that core and sometimes it cannot be identified by vorticity fields. In this work we propose a lagrangian description of the flow to follow particle trajectories and identify the ones which are on the vortex front by utilizing Finite Time Lyapunov Exponents.

\section{Numerical Scheme}

For the realization of simulation used the proposed code by Moeng (1984) and parameterization of sub-grid Sullivan et al. (1994). Was used one spatial domain of $(x 1 ; x 2 ; x 3)=(10 \mathrm{~km}, 10 \mathrm{~km}, 2 \mathrm{~km})$ being the two horizontal earliest and the third vertical. The computational domain consists of a grid of $128 \times 128 \times 128$ points in each spatial dimension. Therefore, the grid spacing is given by $(x=78.125, y=78.125$ and $z=15.625)$. The atmosphere is not static. Geostrophic winds is taken into account for the simulation. The mechanism to reproduce the downdraft is the one proposed by Orf et al. (1996).

In the present study the negative buoyancy that drives the microburst formation is parameterised by imposing an additional source term in the equation for the virtual potential temperature (Anabor et al., 2011).

\section{Finite Time Lyapunov Exponents}

In a lagrangian description of a flow, the particles trajectories are represented by $\mathbf{x}(t)$ and the function

$$
\phi_{t_{0}}^{\tau}: \mathbf{x}\left(t_{0}\right) \rightarrow \mathbf{x}\left(t_{0}+\tau\right)
$$

which maps the particle trajectories from the initial position at $t_{0}$ to the final position at $t_{0}+\tau$. The finite time Lyapunov exponent (FTLE) is defined (Shadden et al., 2006, 2005; Haller e Yuan, 2000; Haller, 2000) as

$$
\Lambda_{t_{0}, \tau}=\frac{1}{|\tau|} \ln \left\|\frac{\mathrm{d} \phi_{t_{0}}^{\tau}(\mathbf{x})}{\mathrm{d} \mathbf{x}}\right\|
$$

and it measures the rate of exponential divergence between particle trajectories within the time interval $\left(t_{0}, t_{0}+\tau\right)$. Then those particles initially close whose trajectories diverge exponentially will have positive FTLE value. This region in the real space where trajectories will exponentially diverge, defines manifolds called $\mathrm{La}$ grangian Coherent Structures (LCS), or finite time hyperbolic manifolds (Haller, 2000) remaining from dynamical systems theory the hyperbolic behavior. This manifolds acts as separatrices or barriers of the flow because the flow across them is null or negligible (Shadden, 2006). The LCS can be identified from a FTLE field because are the ridges (Shadden, 2006) or the local extrema of those fields.

The LCS can be unstable, because particles will diverge, or stable, because particle will converge. By integrating the particle trajectories backward in the time interval is possible to get the stable manifolds. Usually $\Lambda_{t_{0}, \tau}^{+}$represent the FTLE field due to a forward integration in the time interval and $\Lambda_{t_{0}, \tau}^{-}$represent the FTLE field due to a backward integration.

The output of the simulation are the velocity fields. Then in the FTLE algorithm the plane $x z$ is studied, fluid particles are seeded on a regular $640 \times 640$ grid and advected from an initial time $t_{0}$ to a final time $t_{0}+\tau$. The integration to get the particle trajectories is carried out by a fourth order Runge-Kutta aproximation and interpolating the velocity fields.

\section{Results and discussion}

The region of local extrema in the FTLE fields represent the manifolds that acts as separatrices of the flow. In a microburst the movement of particles along the front is such that it curls around the maximum of vorticity or the vortex core. Particles from lower layers ascend and move concentrically around the vortex core in the same 
direction, so this particles represent the edge or front of the microburst. Fluid particles on each side of the edge may aproximate the edge but do not cross it. Hence the edge becomes a region of high stretching and so can be identified as an unstable Lagrangian Coherent Structure. This unstable structures are obtained from forward FTLE fields like those on figures 1,2 and 3. With this method is not possible to get the instantaneous position of the front because is needed to observe the particles trajectories during a time interval. The appropiate time interval, $\tau$, will be the time which takes a particle to move all along the front. Within the timespan of this simulations this approximate time corresponds to $\tau=21$ s.

We show results for the $x z$ plane that slices the center of the domain. Figures 1, 2 and 3 shows $\Lambda_{t_{0}, \tau}^{+}$field for $t_{0}=223,16, t_{0}=247,54 \mathrm{~s}$ and $t_{0}=1049,70 \mathrm{~s}$ respectively. In all this figures the integration time $\tau$ is $21 \mathrm{~s}$, so the initial time of the time interval, changes to follow the evolution of the microburst and we allow a time $\tau$ to observe the particle advection specially on the microburst front. In figure 1 the downdraft recently impinges the ground so the vortex and propagation front is not still developed as in figure 3 . We can observe that the region of higher FTLE values correspond to the front of the Microburst and its sharp definition allows to track the front along the time.

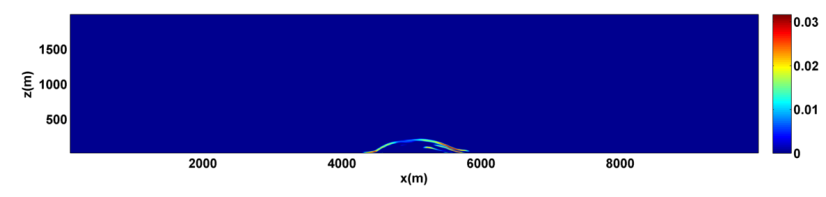

Figura 1: The FTLE ridges specify the Microburst edge. $\Lambda_{t_{0}, \tau}^{+}$field in $s^{-1}$ for $t_{0}=223,16 s, \tau=21 s$.

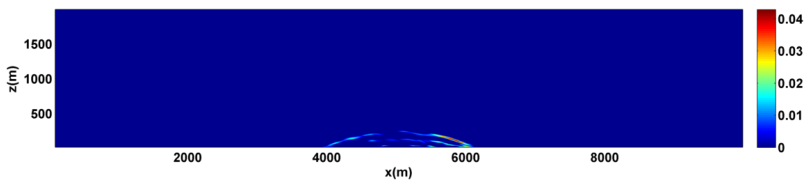

Figura 2: $\Lambda_{t_{0}, \tau}^{+}$field in $s^{-1}$ for $t_{0}=247,54 s, \tau=21 s$.

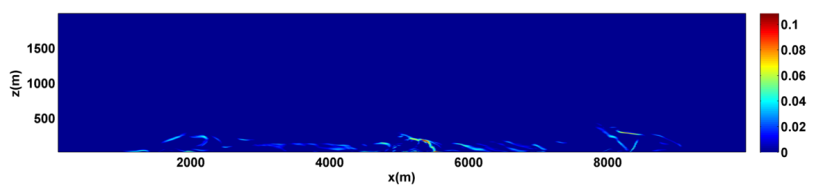

Figura 3: $\Lambda_{t_{0}, \tau}^{+}$field in $s^{-1}$ for $t_{0}=1049,70 s, \tau=21 s$.

\section{Conclusions}

We propose a method to identify and track the displacement of the Microburst front. It can be utilized as well to identify the vortex edge on any situation. This method represent a complement to previous works which were mostly based on eulerian description (velocity and vorticity fields) to study the development of a Microburst. Future research may focus on utilizing lagrangian description, like the FTLE fields or other methods, to study transport and mixing.

\section{Acknowledgements}

We would like to thank to CNPq, CAPES, CNR, PEDECIBA, ANII and CSIC for supporting this research.

\section{Referências}

Anabor, V., Rizza, U., Nascimento, E. L., Degrazia, G. A. (2011). Large-eddy simulation of a microburst. Atmospheric Chemistry and Physics, 11, 9323 - 9331.

Demarco, G., Barrere, N., Sarasua, G., Marti, A. C., Acevedo, O. C., de Nascimento, E. L., Cabeza, C. (2013). Combined effect of jet impingement and density perturbation forcing on the evolution of laboratorysimulated microbursts. Journal of wind engineering and industrial aerodynamics, 123, 69-76.

Fujita, T. (1985). The downburst, microburst and macroburst, satellite and mesometereology research (smrp). Department of geophysical science, 36, 75-86.

Fujita, T. (1990). Downbursts: metereological features and wind field characteristics. Journal of wind engineering and industrial aerodynamics.

Haller, G. (2000). Finding finite-time invariant manifolds in two-dimendional velocity ffields. Chaos, 10, 1-10.

Haller, G., Yuan, G. (2000). Lagrangian coherent structures and mixing in two-dimendional turbulence. Physica $D, 147,352-370$.

Holmes, J., Oliver, S. (2000). An empirical model of a downburst. Engineering structures, 22, 1167-1172.

Lundgren, T., Yao, J., Mansour, N. (2007). Microburst modelling and scalling. Journal of Fluid Mechanics, 239, 461-488.

Moeng, C. H. (1984). A large-eddy-simulation model for the study of planetary boundary layer turbulence. Journal of Atmospheric Science, 41(13), 2052-2062. 
Orf, L. G., Anderson, J. R., Straka, J. M. (1996). A threedimensional numerical analysis of colliding microburst outflow dynamics. Journal of Atmospheric Sciences, 53, 2490-2511.

Proctor, F. (1988). Numerical simulation of an isolated microburst part i:dynamics and structure. Journal of Atmospheric Sciences, 45, 3137-3160.

Proctor, F. (1989). Numerical simulation of an isolated microburst part ii:sensitivity experiments. Journal of Atmospheric Sciences, 46, 2143-2165.

Shadden, S. (2006). A dynamical systems approach to unsteady systems. Tese de Doutorado, California Institute of Technology.

Shadden, S., Leiken, F., Marsden, J. (2005). Definition and properties of lagrangian coherent structures from finite-time lyapunov exponents in two-dimendional aperiodic flows. Physica D, 212, 271-304.

Shadden, S., Dabiri, J., Marsden, J. (2006). Lagrangian analysis of fluid transport in empirical vortex ring flows. Physics of fluids.

Sullivan, P. P., McWilliams, J. C., Moeng, C. H. (1994). A subgrid-scale model for large-eddy simulations of planetary boundary-layer flows. Boundary Layer Meteorology, 71(3), 247-276. 